\title{
Entrevista com Prof. Dr. Marcel Mano (PPGCS/PPGHI/UFU) concedida à Robson Antonio Rodrigues (GEPAEHI/NUPECS/INCIS/UFU)
}

Professor Marcel Mano possui doutorado em Ciências Sociais/Antropologia pela Universidade Estadual de Campinas (2006), mestrado em Antropologia pela Universidade de São Paulo (1996) e graduação em Ciências Sociais (Bacharelado) pela Universidade Estadual Paulista "Júlio de Mesquita Filho" (1990). Trabalhou em diversas instituições de ensino superior nas quais exerceu a docência e atividades de coordenação de Núcleos de Pesquisas e Extensão nas áreas de Cultura e educação patrimonial. Atualmente é professor associado (DE) da Universidade Federal de Uberlândia (UFU) onde desenvolve trabalhos de ensino, pesquisa e extensão, com ênfase nas relações entre Antropologia, Etnologia e História. Nessa mesma instituição é professor permanente e ex-coordenador do Programa de Pós Graduação em Ciências Sociais (mestrado) e professor permanente do Programa de Pós Graduação em História (mestrado e doutorado); é consultor ad hoc da Capes; membro de Conselhos Editorias de Revistas nas áreas de Ciências Sociais e Antropologia; coordenador do GEPAEHI - Grupo de Estudos e Pesquisas em Arqueologia, Etnologia e História Indígena; e foi supervisor do Curso de Especialização em Culturas e Histórias dos Povos Indígenas vinculado ao SISFOR/MEC/SECADI. Seus projetos são desenvolvidos dentro da perspectiva dos itinerários e encontros culturais, com particular atenção às relações de contato e aos contextos de identidades e alteridades indígenas. Tem experiências na área de Ciências Sociais, sobretudo Antropologia, tendo trabalhado nos seguintes temas: Antropologia, Etnografia, Etnologia e História Indígena.

Robson Rodrigues (R.R.): Você pode se apresentar nos contando um pouco de sua trajetória acadêmica e profissional?

Marcel Mano (M.M.): Eu cursei Ciências Sociais na Unesp de Araraquara, e como a grande maioria dos colegas de minha geração tive uma formação marcada pelo marxismo. Desde os anos iniciais da minha graduação frequentei as reuniões do Centro de Estudos Indigenas onde conheci dois profesores que marcaram minha trajetória: a Profa. Dra. Silvia Maria S. de Carvalho e o Prof. Dr. Miguel A. Menéndez. Quando então, mediado por eles, ingressei em discussões acerca das relações entre mito e práxis, não tive dúvidas do que quería fazer! Fui então orientando do Miguel (que faleceu precocemente) e pelas suas mãos inserido na etnohistória e na etnografía dos povos Tupi da Amazônia central, área Madeira - Tapajós, em especial os Mawé, que pesquisei na graduação e no mestrado. Ainda pelas mãos do Prof. Miguel participei do Núcleo de História Indígena e do Indigenismo de onde fui arremesado ao mestrado no PPGAS da USP. Lá aprendi o estrturalismo com a Profa. Manuela Carneiro da Cunha, a Antropologia Ecológica com o Prof. Walter Alves Neves e a ecología cultural e humana das populações amazônicas com a Profa. Renate B. Viertler, minha gentil e acolhedora orientadora após a morte do Miguel. Com o título de mestre fui dar aulas. 
Ministrei Antropologia em diferentes cursos de graduação e faculdades particulares, a maioria delas sem um plano de carreira ou interesse em pesquisa. Quando já decepecionado em trilhar apenas a carreira do magisterio, tive a oportunidade de ser contratado por uma dessas Universidades para lecionar e pesquisar. Foi a deixa: dessas pesquisas fui cursar o doutorado na Unicamp sob a orientação do Prof. John M. Monteiro (que também faleceu precocemente). O doutorado representou uma guinada no campo de investigações que até então havia traçado: da etnografía e etnohistoria amazônica para a história indígena no interior paulista. Depois do doutorado, e graças às políticas educacionais dos governos Lula, ingressei na carreira publica do magisterio superior- Antropologia- na Universidade Federal de Uberlândia. Atualmente sou profesor associado do Instituto de Ciências Sociais e profesor permanente do PPGCS Programa de Pós-Graduação em Ciências Sociais- e PPGHI - Programa de Pós-Graduação em História da UFU.

R.R.: Quando e como começou seu interesse pela antropologia e pelas questões indígenas?

M.M.: Sempre fui fascinado pelas histórias de meu "nono" materno, repleta de índios e cawboys que ele contava à la roteiro dos filmes de faroeste da época. Brincava de "forte apache" e aprendi a relativizar Rin tin tin aos poucos, ao ouvir Língua de Trapo, estudar etnologia indígena e a praticar etnografia. Ingressei na graduação em Ciências Sociais com esse horizonte inconsciente formado durante minha infância, e com a certeza consciente de querer estudar modos de vida e pensamentos diferentes que me encantavam nos discos e nos livros que descobria durante o Ensino Médio (entre os quais James Hilton, Carlos Castñeda, Adoulx Huxley e Richard Bach). Então tinha tudo para ir para as Ciências Humanas. Mas foi durante as aulas iniciais da graduação e sobretudo a participação nas reuniões do Centro de Estudos Indígenas da Unesp/Araraquara que confirmaram para mim os caminhos de estudos e pesquisas que queria trilhar.

R.R.: Por que você se interessou pela história indígena?

M.M.: A historia indígena sempre esteve presente nas discussões e temas com os quais me deparei desde os tempos de graduação. As primeiras pesquisas com os Mawé sob as orientações do Prof. Miguel Menéndez já me conduziam a ela. Afinal, a problemática etnográfica Mawé (grupos mistos e/ou tupinizados) só podia ser resolvida pela história. Como 


\section{Nanduty}

explicar um povo indígena, de língua não tupi-guarani do Tronco Tupi, que apresentava em sua cosmologia e tecnologia material aspectos de influência Karib e Aruak? "Tupi or not tupi"? era essa a questão. E não havia meio de enfrenta-la senão se remetendo à uma complexa rede de contatos intertribais e interétnicos cujo passado podia ser remontado, mesmo que palidamente, desde o século XVII. Então, sempre me interessei pela história indígena, mas foi o doutorado que representou, como disse antes, uma guinada definitiva. Nele não havia uma realidade etnográfica presente, mas um passado de ocupações indígenas que pretendia reconstituir no diálogo entre a Antropologia -Etnologia Indígena-, a Arqueologia e a História.

R.R.: Dos campos de Araraquara você seguiu para a província de Goiás. Como foi esse movimento?

M.M.: Esse movimento não representou uma transição ou uma mudança de direção. Ele simplesmente foi a continuidade das pesquisas iniciais sobre as ocupações indígenas na região norte do atual estado de São Paulo, documentalmente conhecida como Campos de Araraquara, que resultaram na tese de doutorado. Essa era uma área histórica que só podia ser entendida a partir da documentação e da cartografia dos séculos XVII ao XX. Em parte, foram elas -a documentação e a cartografia- que me levaram ao Triângulo Mineiro e ao sul de Goiás que, no XVIII, pertenciam à Capitania de Goiás. Por outra parte também já havia entendido que o norte paulista era uma área de fronteira cultural entre ocupações indígenas diferentes, entre as quais grupos conhecidos pelo termo genérico "Cayapó". A partir do norte de São Paulo, em direção ao Triângulo Mineiro, sul de Goiás e leste do Mato Grosso do Sul apresentava-se uma ampla ocupação desses grupos indígenas (atestada tanto pela documentação como pela arqueologia) que ainda era pouco estudada. As escolhas de novos temas de pesquisas que conduziram à Província de Goiás foram então naturais e não representaram um abandono das discussões acerca das ocupações indígenas no norte de São Paulo. Apenas ampliaram a abrangência espacial, em parte levado pela própria documentação, e em parte pela certeza de relações históricas e culturais entre grupos indígenas que no passado ocupavam não apenas o quadrilátero entre as bacias do Tiête, do Mogi-Guaçu, do Grande e do Paraná no interior paulista, mas também às ocupações indígenas das bacias dos rios Grande e Paranaíba, nos atuais Triângulo Mineiro e sul de Goiás. 


\section{R.R.: Atualmente como você vem pensando a história indígena?}

M.M.: Estou inclinado a pensar a história indígena a partir de um modelo que se aproximaria da imagem de uma mandala, ou rizoma nos termos de Deléuze e Gautarri. Levaram-me a isso as pesquisas com a história dos contatos dos Jê meridionais -"Cayapó" com seus diferentes outros nos séculos XVIII e XIX. No decorrer de quase uma década de pesquisas percebi que as avaliações e ações históricas desses grupos dos Jê foram mutáveis e cambiáveis a depender do sistema de identidades e alteridades, dos sujeitos, dos signos e dos interesses envolvidos nos contatos. Guerras, saques, alianças, comércio, aparentamento, aldeamento não foram estratégias excludentes entre si, e ações tomadas em um determinado espaço-tempo foram facilmente alteradas em outros espaços-tempos. Havia, por assim dizer, uma variedade de avaliações simbólicas das alteridades e, em consequência, uma variedade de ações históricas que apontavam a existência de múltiplos e cambiáveis trajetos históricos.

Esses dados não nos confirmavam nem o modelo de uma história fásica ou linear que conduziu da autonomia à extinção, nem o modelo de uma história espiral e ascendente que confrontou aculturação e resistência, nem mesmo uma história cíclica e reiterativa de perenidade. O problema inerente a todas as histórias indígenas que aí se desenvolveram parece, com base nesses dados empíricos, ser sua própria raiz binária. Os eventos dos contatos até agora pesquisados mostram a coexistência de avaliações e ações diferentes, resultando assim numa história das possibilidades. À luz desses dados, a história desses grupos parece não desenhar uma linha reta ou uma estrutura sobre a qual se aplica uma lei geral. No lugar de uma estrutura centrada com pontos fixos, etapas, ciclos ou fases, essa história inspira a dispersão, a transitoriedade, a fluidez e o movimento. Por isso, penso, se quisermos uma nova história indígena desenhada com base no protagonismo e na ação política consciente dos indígenas, devemos reconhecer uma diversidade (quase) infinita de temporalidades, ações, objetivações, subjetivações e marcações históricas, uma história constituída por tempos e espaços descontínuos, fora das sequencias tradicionais. Essas histórias devem fugir das generalizações, pois não há ritmo nem caminho únicos e nem, talvez, um suposto grupo de atuação homogêneo definido na eternidade. Se acompanharmos a história dos contatos dos grupos Jê meridionais observaremos que eles não construíram suas opções entre a aculturação e a resistência; a tradição e a modernidade; a perenidade e extermínio, o etnocídio e a etnogênese. Essa história nos mostra, de fato, como as direções tomadas foram múltiplas e, 
mesmo depois de tomadas, cambiáveis, com movimentos que se assemelham aos das "mandalas". Então, como penso, uma nova visão dessa história indígena deve brotar de uma imagem mais próxima à das madalas e dos rizomas.

R.R.: É possível estabelecer um diálogo com outras áreas do conhecimento para se pensar a história indígena?

M.M.: Não é apenas possível. É inevitável! Os dados históricos não falam por si; e os documentos não condensam uma incontestável realidade empírica. Desde os ensinamentos da filosofia hermenêutica e da Antropologia interpretativa precisamos considerar que o autor do documento, como o sujeito informante (por falta de um termo melhor), é um intérprete no sentido de Dilthey: um ser vivo situado cultural e historicamente e com determinadas capacidades cognitivas. Por isso, ambos -autor do documento e sujeito informante- são intérpretes de uma realidade; assim como são os historiadores e antropólogos. Se a associação pode ser empregada entre o historiador (que recolhe interpretação nos documentos) e o antropólogo como interprete de segunda mão nas palavras de Geertz, há de fato enormes problemas em considerar de forma literal as informações etnográficas contidas nos documentos históricos. Há nelas, obviamente, interpretações que podemos considerar como alegorias da colonização, muitas das quais repetidas à exaustão. Em alguns casos, inadvertidamente tomadas por alguns intérpretes como realidade, essas alegorias foram reproduzidas como dogmas por historiografias regionais. Neste caso, melhor posicionado para tentar fugir dessas alegorias estará o leitor acostumado não só com a História, mas com a Antropologia, a Arqueologia, a Etnografia e a Etnologia Indígenas. É com base em inferências etnográficas e arqueológicas consistentes que ele pode recolher sinais, pistas ou indícios nas palavras de Ginzburg, que permitem colocar os dados documentais em um quadro comparativo mais abrangente. Se o protagonismo indígena que procuramos se encontra entre os signos culturais e os interesses pragmáticos, os dados documentais precisam ser interpretados a partir de projeções etnográficas. O uso de informações provenientes da Arqueologia e da Etnologia facilitarão ao pesquisador não só a garimpagem de informações documentais, como a sua interpretação. Considero, pois, que o uso do material de pesquisa da história -documentos históricos- a partir da perspectiva da alteridade -objeto da 


\section{Nanduty}

Antropologia- só pode ser feita com base no diálogo interdisciplinar entre Antropologia, Etnologia, Arqueologia e História Indígena.

R.R.: Como você pensa a relação entre a história e o pensamento mítico das populações indígenas?

M.M.: Essa não é uma pergunta fácil ou rápida de responder. Ela me acompanha desde os trabalhos iniciais na graduação a partir do diálogo com o marxismo antropológico. De lá prá cá muita coisa mudou, mas essa continua a ser para mim uma questão inquietante. Seu debate é longo na Antropologia e as discussões acaloradas implicaram em considerar tanto uma filosofia do homem como uma filosofia do conhecimento. No primeiro caso basta lembramos as controvérsias entre Lévi-Strauss e Sartre nos anos 1960 sobre o fundamento do homem: estaria na história e na dialética como quer o filósofo, ou nos sistemas de diferenças e propriedades comuns atemporais como quer o etnólogo? No segundo caso, por mais de cento e cinquenta anos a Antropologia e os antropólogos oscilaram na interpretação da cultura: estaria ela relacionada, como Sahlins denominou, a uma razão prática ou a uma razão simbólica? ou na síntese dialética entre ambas? Isso implica, para a pergunta que vocês me fazem, considerar que o lugar do homem e do conhecimento estão nas relações entre as estruturas culturais (o pensamento classificatório) e os eventos materiais (a prática histórica e política).

Com base nisso, e para tentar responder à pergunta, não acho que o mito (a narrativa mitológica) seja o que para nós é uma narrativa histórica. Mas acho que os povos indígenas têm tanto uma consciência mítica como uma consciência histórica de si e dos outros povos. Sou sempre propenso a pensar o mito (ou o pensamento mítico) à maneira do estruturalismo: um metacódigo do qual ele -o mito- é o único usuário. O mito não fala do mundo, embora retire sua substancia do concreto, mas fala do próprio pensamento que o produziu. Vejam a censura que Lévi-Strauss lança à psicanálise: a de que não podemos reduzir o pensamento mítico a um único código. Neste caso, sejam códigos psico-orgânicos ou históricos, nos mitos eles se apresentam como modalidades da contingência e não da necessidade. Como nessa perspectiva o mito trabalha com vários códigos simultaneamente num processo de transformações analógicas que levam de um ao outro, as virtualidades de suas leituras são múltiplas, e Lévi-Strauss mostrou isso em diferentes ocasiões. 
Mas há nessa maneira de pensar os mitos ao menos duas ou três implicações importantes que nos conduzem além do estruturalismo. A primeira é o entendimento de que essa estrutura ou lógica associacionista não é dada a priori. Se Lévi-Strauss demonstrou, superando Durkheim, Mauss, Malinowski, Lévi-Bruhl, Meyer-Fortes, Firth entre outros que a classificação e o pensamento simbólico são da ordem do intelecto; hoje é importante reconhecer que essa estrutura do intelecto não é dada como uma substância biológica inata ou transcendental. Tim Ingold tem recentemente sustentado, contra as concepções neodarwinistas e cognitivistas de Dan Sperber, por exemplo, que o organismo não retira do ambiente as representações que irão atender a uma estrutura vazia de conteúdo; mas que já é imersa no ambiente que se formam as conexões neurológicas, a musculatura e a anatomia dessa estrutura. É, portanto, em uma totalidade indivisível entre organismo - ambiente que o indivíduo se forma, postura que, ao meu ver, retoma a dialética que desconfiava esquecida na maior parte dos marxismos desde os tempos da graduação. Se estivermos corretos podemos então afirmar que a estrutura existe e que, até certo ponto, suas leis se desenvolvem de maneira inconsciente; mas também podemos afirmar que ela não é inata, mas é desenvolvida no decorrer da atividade humana. Dados da evolução humana parecem mesmo indicar que a hominização -a constituição biológica do homem e de seu cérebro- se desenvolveu em relação aos processos de humanização -a construção do mundo cultural-, como já lembrava Geertz. Sobre isso, lembro ainda das aulas da Profa. Silvia Carvalho nas quais ela dizia que se a estrutura é de matriz binária, ela se desenvolveu com a práxis primordial da caça e coleta (“o toma lá, dá cá" da divisão sexual das atividades). Seja como for, temos de superar os dualismos entre razão prática e razão simbólica em favor de uma visão na qual o pensamento classificatório e o mundo se constroem mutuamente.

A segunda implicação em pensar o mito à maneira do estruturalismo é entender que, embora o mito não possa ser confundido com o que entendemos em nossas sociedades como narrativa histórica, ele desempenha sim um papel na história. Os estudos de Sahlins sobre o contato dos havaianos com a expedição do capitão Cook no século XVIII inauguraram as bases de uma antropologia estrutural e histórica que Sartre nos anos 1960 já reclamava em suas polêmicas com Lévi-Strauss. Sahlins sustenta que, no confronto entre lógicas culturais distintas -cujo estudos de contatos são privilegiados-, um primeiro momento é o da reprodução da estrutura, ou seja, a interpretação do acontecimento segundo as categorias culturais pré-existentes. Aí a história é culturalmente ordenada -o que não se distancia muito 
do horizonte de Lévi-Strauss. Mas, e isso é o importante na proposta de Sahlins, o momento de interpretação do acontecimento, isto é, de prática da estrutura, permite constituir-se numa estrutura da prática, na qual intervém projetos e interesses - muitas vezes conflitantes - dos agentes e categorias sociais envolvidas, e tal intervenção pode representar não mais a reprodução da estrutura, mas a sua transformação.

A “mito-práxis" de Sahlins permitiu então avançar em relação aos estudos semióticos e estruturalistas que, embora desvendando uma lógica formal, esterilizaram as transformações históricas. Com isso aprendemos algumas coisas. Primeira: a que o valor simbólico do signo não é intrínseco, mas se constrói e se atualiza em interação relacional aos sujeitos, circunstâncias, interesses e motivações dadas num certo momento. Segundo: que a história também é feita de processos estruturais inconscientes e conteúdos históricos conscientes. Terceiro: que a transformação da cultura -ou do valor do signo- também é modo de sua reprodução; tal como, ainda sem abandonar o estruturalismo, a Profa. Manuela Carneiro da Cunha recorreu aos sinais diacríticos em suas discussões sobre identidade e etnicidade. Permita dizer, foi com base nesse debate que desenvolvemos as primeiras pesquisas sobre a guerra e o comércio na história dos contatos de grupos Jê meridionais no norte de São Paulo, Triangulo Mineiro e sul de Goiás.

E finalmente, a terceira implicação em pensar o mito à maneira do estruturalismo consiste, para mim, em um grande mal-entendido. Intérpretes desavisados quiseram ver na clássica formulação do modelo de sociedades frias e sociedades quentes uma divisão entre sociedades sem e com histórica, sociedades míticas e sociedades históricas. Como LéviStrauss mostrou em diversas ocasiões, todas as sociedades estão na história e fazem sua história. O que é próprio a cada uma das sociedades é a sua forma de subjetivação histórica (novamente o debate com Sartre pode ser ilustrativo), o que equivale a dizer que para LéviStrauss a história não está no campo da objetividade, mas no da subjetividade. A diferença não é, portanto, de ter ou não história (o que soa absurdo), mas em como são diferentes as temporalidades, as marcações, as objetivações e as subjetivações históricas de cada povo; o que inevitavelmente conduz à formação e incorporação de distintas noções de tempo, espaço, história e memória, incompatível com o modelo binário de sociedades frias e quentes. E o próprio Lévi-Strauss também já alertava para isso. Disse ele em um de seus escritos que "nenhuma sociedade é absolutamente fria ou quente, essas são apenas formulações teóricas" e que, em verdade, "as sociedades empíricas distribuem-se ao longo de uma linha em que 
nenhuma delas ocupa os polos". Portanto não são nos polos do modelo que devemos buscar a história, mas no continuum de possibilidades, o que para mim parece definitivamente aproximar o estruturalismo do pós-estruturalismo em Antropologia.

Assim sendo, mito (estrutura, pensamento classificatório) e história (evento, condições pragmáticas) se encontram e se tocam em algum ponto desse continuum, a depender das sociedades estarem mais próximas ou distantes de um dos polos. Desde pelo menos os anos 1980 os inúmeros estudos sobre as representações dos não índios nas cosmologias ameríndias serviram para entender como as sociedades indígenas têm ambas consciências: mítica e histórica de si mesmas e de outros povos. Foi Lévi-Strauss em A história do lince que mostrou como a mitologia ameríndia dispunha de elementos ideológicos no qual o lugar dos invasores já estava reservado antes mesmo de sua chegada. Mas foi o trabalho de uma série de outros pesquisadores, muitos dos quais no Brasil reunidos no NHII que vieram demonstrar o desenvolvimento de uma consciência histórica entre as sociedades ameríndias. Penso, como Sahlins, que acionada pelo evento histórico a estrutura cultural se apropria do evento e se reproduz, pelo menos até certo ponto do contato, quando seus significados têm de ser atualizados pelas circunstâncias históricas e políticas. Creio que o protagonismo indígena que em cada caso particular procuramos pode ser encontrado nas relações entre esses signos culturais e os interesses e condições históricas -o que tem a ver com uma concepção de homem, de história e de conhecimento. Então, como entendo, uma consciência histórica só pode se desenvolver em relação a uma práxis histórica, e neste caso infelizmente dispomos apenas do período pós contato como campo de investigação. Compartilho de uma tendência que, desde os anos 1980, entende que são as representações dos não índios nas cosmologias indígenas, ou a teoria dos indígenas sobre nós não indígenas, que de fato marcam um campo investigável sobre a consciência e as narrativas históricas dos povos indígenas.

R.R.: Como você vê a antropologia no período contemporâneo?

M.M.: Com grandes e ótimos desafios. Desafios que, se resolvidos, colocarão a Antropologia na vanguarda das teorias renovadoras das ciências humanas. Como sabemos, a nossa disciplina é originalmente um produto do colonialismo. E o colonialismo, como enfatizou Roger Bastide, é um fato social total. Nossa experiência colonial nos afetou então, em todas as dimensões, inclusive na nossa forma de pensar. Durante muito tempo as Antropologias do 
cone sul, como seus países, foram dependentes das Antropologias do cone norte. Vejam os trabalhos dos ingleses na África e dos franceses e estadunidenses entre nós. Foi dessa colonialidade do saber que brotou uma explicação etnológica de nós plasmada por olhares externos. Se dermos uma olhada nos conceitos importados pela Antropologia no Brasil entre os anos 1940 e 1970, veremos que hoje a maioria teve de se render à realidade etnográfica. Mesmo as ficções mais persuasivas da Antropologia, como diria Marilyn Strathern, não resistiram. Todas parecem ter se rendido à ilusão de Malinowski quando, ao querer "apreender o ponto de vista do nativo", construiu a cultura a partir de sua teoria das necessidades. Ao se trair, a Antropologia nos surpreendeu com o fato de que a significação do objeto participa da nossa construção do objeto. Verdade antiga, na prática a quebra das amarras da colonialidade dos saberes e fazeres antropológicos demorou para ocorrer.

Pois é aí que nos encontramos. No ponto no qual reconhecemos, com Roy Wagner, que "nós" inventamos a cultura, e no esforço de conformá-la à toda humanidade, inventamos a Antropologia e, neste caso, os outros foram pensados à base de categorias e conceitos que pertencem ao nosso contexto simbólico. Portanto, não nos interessa mais o que as teorias antropológicas pensam dos outros povos, mas, em uma antropologia reversa como diria esse mesmo autor, como os outros povos constroem e sustentam uma significação de si e de nós: uma teoria nativa dos nativos e uma teoria nativa de nós.

É apenas durante o advento do capitalismo global e da sociedade da informação que a emergência de intelectuais de ex-coloniais (Bhabha, Said, Stuart-Hall, Dirlik) passaram a lançar uma crítica veemente aos modelos teóricos que retiravam da experiência histórica de países hegemônicos (sociedades do Atlântico Norte) os modelos explicativos para os outros povos. Eram as primeiras críticas à hegemonia política, social, econômica etc. e às distinções cognitivas: centro - periferia, primeiro mundo - terceiro mundo, desenvolvimento subdesenvolvimento, sociedades capitalistas - sociedades pré-capitalistas etc. que impregnaram o imaginário e a prática dos contextos coloniais. Teorias e práticas foram denunciadas, certezas foram removidas. Entre elas uma central: a do olhar distanciado, já que uma antropologia nativa -pos-colonial ou decolonial- se realiza no encurtamento da distância entre sujeito e objeto e, atualmente, na completa supressão dessa distância com a emergência de intelectuais indígenas.

Neste ponto parece haver dois movimentos não excludentes. A construção de novas teorias antropológicas por intelectuais não indígenas fora dos centros do norte; e a emergência 
de intelectuais indígenas. No Brasil, vemos as renovações propostas pelo Prof. Eduardo Viveiros de Castro para o problema das ontologias amazônicas e para o dravidianato amazônico a partir daquilo que ele intitula de "levar a sério o que dizem os informantes" como exemplo desse primeiro movimento; e os impactos da sabedoria de um xamã Yanomami em A queda do céu como exemplo do segundo. A proliferação de pesquisas colaborativas como as de Davi Kopenawa e Bruce Albert, de antropologias por demanda, de apropriações e críticas indígena dos discursos e conceitos acadêmicos etc. parecem estar suprimindo em definitivo as barreiras entre antropólogos e indígenas. Nossos objetos se deslocam e o desafio nos é dado na tarefa de destruição, reconstrução, recombinação de nossas teorias, de nós mesmos e de nossas teorias sobre os outros, em relação simétrica às teorias dos outros, deles sobre si mesmos e das teorias deles sobre nós. E isso pode nos revelar um completo descentramento, pois não poderemos mais olhar o mundo à base de estruturas; mas de malhas, fluxos, rizomas e redes não estruturadas. Se estiver correto, nossos desafios são o de remodelar a forma de pesar e fazer Antropologia, reinventando-a aos avessos e vis-à-vis consigo mesma.

R.R.: E como vem pensando a possibilidade de construção de novos modelos interpretativos a partir das teorias antropológicas contemporâneas?

M.M.: Parafraseando Lévi-Strauss em sua referência aos totens, os modelos são bons para pensar. Eles são formulações teóricas para uma realidade que teima em fugir deles. Por isso, quando nas minhas pesquisas com as histórias dos contatos dos grupos Jê meridionais "Cayapó"- comecei a usar os modelos da etnologia Jê, da tradição arqueológica AratuSapucai, e da história indígena para pensar o contexto dos séculos XVIII e XIX, os dados históricos começaram a esmorecer certezas e o modelo teve de necessariamente mudar. A começar pelo seu princípio básico: o dualismo, o que implica obviamente numa tentativa de superação das antropologias clássicas no caminho das teorias pós-estruturalistas. Com base nisso, e de acordo com os dados empíricos, a superação do dualismo não pôde, porém, se contentar com uma solução dialética que levava do dualismo à unidade dos contrários, essa, aliás, implícita na própria noção de dualismo em geral e do dualismo Jê em particular. Para além da unidade, a superação nos conduziu à multiplicidade, a agenciamentos que mudavam de direção, que se tocavam, se separavam e se reconectavam, com movimentos que se assemelhavam à caracterização do rizoma por Deleuze e Guatarri. 
Para melhor explicar, permita-me voltar a um modelo que evoquei quando acima vocês me perguntaram sobre a visão da história indígena. Como ela, já propus também que as relações de identidades e alteridades entre esses grupos dos Jê meridionais durante o período e a região desenharam uma mandala e não círculos concêntricos ou linhas diametrais binárias. Ao contrario desses dois últimos, o modelo em forma de mandala expressa a descentralização, enfatiza as interfaces entre os diferentes sujeitos, categorias e contextos envolvidos nas relações de contatos, e enfoca processos de criação/recriação daquilo que Bhabha chamou de "entre-lugares", fronteiras culturais porosas onde se cruzam, se sobrepõem, se retraem e se expandem uma multiplicidade de agenciamentos históricos.

No desenho da mandala cada ponto de intersecção possível, construído e reconstruído por meio dos movimentos dos sujeitos, pode gerar mesclas híbridas e sobreposições de duas, três, quatro ou mais possibilidades, todas não necessariamente duradouras porque podem ser desmontadas e remontadas, abertas e fechadas, quebradas e rearranjadas etc.. Portanto, a vantagem desse modelo é permitir pensar como múltiplas e dinâmicas as facetas das intersecções. No contexto dos Jê meridionais, no qual eram múltiplos os sujeitos históricos em ação, as possibilidades de intersecções e os processos de construção/destruição/reconstrução porosas de fronteiras, as possíveis formas da mandala, nunca assumiram uma mesma direção nem foram dadas a priori. Em cada caso o resultado do agenciamento foi inesperado, imprevisível, constantemente construído e reconstruído à medida de suas conexões, direções e intersecções espaciais e temporais com seus múltiplos outros. Neste caso, a temporalidade das conduções dos movimentos, isto é, das ações e eventos, apontaram para um misto simultâneo, cambiante e transformativo (e não dicotômico e fixo) de signos e interesses; necessidades e contingências; conteúdos conscientes e processos inconscientes; permanências e mudanças; inovações e reinvenções; transformação e reprodução; continuidades e descontinuidades. Neste novo mundo já não se podia mais aplicar uma estrutura centrada.

R.R.: Os modelos teóricos se constituem em elementos estruturantes na antropologia. Nessa perspectiva como os modelos podem continuar a provocar o pensamento na atualidade?

M.M.: Acho que essa questão está implícita nas outras. Os modelos surgem da interação entre a realidade e o pensamento que sobre ela se aplica, mas uma vez depurado em um conceito ou 


\section{Nanduty}

uma lei, os modelos têm de voltar à realidade da qual partiram. Os modelos sempre serão construções teóricas aproximativas da realidade, e não a realidade em si. Enquanto tais, os modelos não existem em estado puro. Vejam, por exemplo, as denúncias de Bruno Latour e da antropologia simétrica aos marcadores modernos de separação entre Natureza e Cultura que impregnaram as antropologias clássicas. Por isso, os modelos sempre provocarão o pensamento quando confrontados com a realidade. Pesquisar não é testar um modelo cujo resultado está antecipado na hipótese; isto é reprodução. Pelo contrário, pesquisar é confrontar o modelo/hipótese com a realidade, focar nas suas possibilidades e limitações, e propor uma nova forma modelo/hipótese de repensar a realidade, num movimento continuo e dinâmico. Sem isso, não há desenvolvimento, nem crítica e nem superação.

R.R.: Para finalizar fale um pouco sobre como tem sido seu trabalho de pesquisa na UFU?

M.M.: As minhas pesquisas veem sendo desenvolvidas a partir da perspectiva dos itinerários e encontros culturais, com particular atenção às relações de contatos e aos contextos de identidades e alteridades indígenas. Os diferentes projetos desenvolvidos se articulam em um esforço mais amplo para pensar a ação histórica dos sujeitos sociais a partir da perspectiva das alteridades. Com base na história dos contatos de grupos Jê meridionais, documentalmente apresentados como "Cayapó", esse esforço quer intervir na discussão da construção simbólica e histórica das experiências de contatos. O cenário desses grupos dos Jê durante o período colonial tem encaminhado para o estudo de uma complexa e intricada rede não estruturada de identidades e alteridades, de avaliações simbólicas e estratégias pragmáticas de contatos diferentes e cambiantes entre esses grupos indígenas e seus diferentes outros: agentes coloniais não-índios, índios autóctones, índios transladados e aldeados, negros escravos, negros fugidos e quilombolas, mestiços e homens livres pobres etc. Por isso me são caros os diferentes motivos, estratégias e processos históricos de agenciamentos desses grupos indígenas durante as suas relações de contatos, com enfoque nas tensões entre as políticas indigenistas e as políticas indígenas, os trajetos históricos desses grupos e os processos de etnogênese, as relações entre signos culturais e interesses pragmáticos em cada caso particular de contato, as avaliações simbólicas das alteridades e as políticas indígenas de controle, as redes de identidades e alteridades movidas por esses grupos, enfim... Como afirmei anteriormente, são os resultados dessas pesquisas que têm me encaminhado neste caso concreto para a reflexão da história indígena e do sistema de identidades e alteridades como 


\section{Nanduty}

fluxos, compostos de "entre-lugares", hibridações, combinações e agenciamentos em redes não estruturadas que já não se encaixam nos modelos binários, fixos e rígidos até então usados na interpretação da Arqueologia, da Etnologia e da História Indígena desses grupos.

Além dos projetos de pesquisas sobre os contextos dos contatos dos Jê meridionais “Cayapó"- nos séculos XVIII e XIX, mais recentemente, e em face de uma antiga e crescente demanda do Movimento Indígena da Região do Triângulo Mineiro e Alto Paranaíba, venho trabalhando na elaboração de pesquisa colaborativa acerca das Memórias Indígenas no Triângulo Mineiro e Alto Paranaíba. Com o auxílio dos colegas que integram o Grupo de Estudos e Pesquisas em Arqueologia, Etnologia e História Indígena do PPGCS, PPGHI e FACIP UFU, e em colaboração com os indígenas não aldeados da região, o projeto pretenderá mapear as presenças, as trajetórias e as lutas de indígenas citadinos, urbanos, não aldeados ou desaldeados que vivem em diferentes cidades do Triângulo Mineiro e Alto Paranaíba.

...Acho que é isso.... 